\title{
Models for humanitarian logistics
}

\author{
F. Russo \& M. R. Trecozzi \\ Università degli Studi Mediterranea di Reggio Calabria, \\ DIMET, Dipartimento di Informatica, Matematica, \\ Elettronica e Trasporti, Italy
}

\begin{abstract}
Emergency logistics is a process to organize and distribute resources during emergency conditions in the area affected by a disastrous event. By means of emergency logistics is possible to reduce disaster impacts that are natural or anthropic, after an event has occurred. During emergency conditions planning is needed to continue evacuation activities after the time when the final effects occur and people cannot be rescued. For evacuation activities resources must be identified to allocate in the area affected of the disastrous event according to elementary work classes.

In this paper we focus on resources, in particular we consider the relief vehicles and their distribution channels. We propose two distribution channel models: the first one is transhipment, when the relief vehicles go to the emergency area with one contact point; the second model is point to point, when the relief vehicles go to the emergency area without any contact point. Keywords: emergency condition, relief vehicles, distribution channels.
\end{abstract}

\section{Introduction}

Risk (R) can be evaluated in probabilistic terms by basic components: occurrence $(\mathrm{P})$ of an event in terms of probability or frequency of a specific event actually happening; vulnerability $(\mathrm{V})$, related to the resistance of the infrastructures when the event occurs; exposure $(\mathrm{N})$, that is an equivalent homogeneous weighted value of people, goods and infrastructures affected during and after the event [1-3]. The general equation of risk can be written in the form:

$$
\mathrm{R}=\mathrm{PVN}
$$


Risk can be reduced acting on the basic components by prevention activities to reduce occurrence and by protection activities to reduce vulnerability or/and exposure. In this paper we consider activities to reduce exposure. The main activity to reduce exposure is evacuation, which consists of reducing the number of users and goods that can experience negative effects when emergency events occur.

In Section 2 an introducing state of art is presented (2.1) according to disastrous event temporal evolution (2.2) and identifying zoning, work classes and resources in the affected area (2.3). In Section 3 distribution channels are analysed: Point to point and Transhipment. In Section 4 conclusions are reported.

\section{State of art}

\subsection{General definition}

Emergency logistics is the key to alleviate the impact of disasters, natural and not, in the period immediately following their occurrence [4]. In literature the definition of emergency logistics has not been well clarified and it is different from the definition of business logistics which has been stated clearly. It is possible to provide a definition of emergency logistics as a process characterized by four main facets:

- Planning, management and control the efficient flows of relief, information, and services from the points of origin to the points of destination to meet the urgent needs of the affected people.

- Timeliness control of relief supply and distribution, particularly in the critical 3-day period after the disaster occurrence. This can be explicated in two different facets: inbound logistics to relief distribution centers, termed the relief supply phase, and outbound logistics from relief distribution centers to affected areas, termed the relief distribution phase. During the relief supply phase the aim is to acquire relief supplies from multiple suppliers to relief distribution centers. In the inbound logistics phase there are operational problems from the difficulties in identifying the relief supply sources, as well as coordinating the supplied relief for quickly responding to the urgent needs of the affected people. During the relief distribution phase the aim is to delivery relief supply from distribution centers to the affected areas to satisfy the urgent needs of people. In outbound logistics there are operational problems from the difficulties in reliability of damaged infrastructures and their effects on the accessibility to an affected area, amplifying the complexity and difficulty in time-based emergency logistics control.

- Management of resources is challenging, because relief distribution operations and the corresponding resources are unknown and readily controllable to logistics suppliers.

- Real-time relief demand information is challenging, because it is required but almost inaccessible after the disaster occurrence. 
From the four main facets above derives the following emergency logistic definition:

Emergency logistics is the process of planning, management and control of the efficient flows of relief, information, and services from the points of origin to the points of destination to meet the urgent needs of the affected people, where timeliness control of relief supply and distribution, management resources and real-time relief demand information is challenging.

\subsection{Temporal evolution}

Exposure activities for each disastrous event can be classified with respect to the time slice that is the period over which a generic event evolves. The time slice varies according to the scenario: several years for long term, some months or days for short term, some days or hours or minutes for now-casting. Within the time slice $\Delta$, four main intervals have to be defined $\left(\Delta_{0}, \Delta_{1}, \Delta_{2}, \Delta_{3}\right)[5,6]$ :

- $\Delta_{0}=\left(\mathrm{t}_{0}, \mathrm{t}_{1}\right]$ between the times

$t_{0}$, the time when the study of the evacuation plan is started;

$t_{1}$, the time when the hazardous event is known to happen or supposed forecasted;

- $\Delta_{1}=\left(\mathrm{t}_{1}, \mathrm{t}_{2}\right]$ between the times $\mathrm{t}_{2}$ and $\mathrm{t}_{3}$, the time when the threat occurs and becomes a dangerous event and starts its effects;

- $\Delta_{2}=\left(\mathrm{t}_{2}, \mathrm{t}_{3}\right]$ between times $\mathrm{t}_{2}$ and $\mathrm{t}_{3}$, the time when the final effect occurs and people cannot be rescued;

- $\Delta_{3}=\left(\mathrm{t}_{3}, \mathrm{t}_{4}\right]$ between times $\mathrm{t}_{3}$ and $\mathrm{t} 4$, the time when the hazardous event ceases its effect on the population.

Risk assessment consists of evaluating the possible threats and their relative evolution in the possible intervals $\Delta_{1}, \Delta_{2}$ and $\Delta_{3}$.

Exposure activities that can be carried out are different according to the time slice. In order to save all the population, evacuation activities must be activated before the event occurs $\left(t_{1}\right)$, considering preparedness and mitigation [1-6]. They terminate when the final effect occurs $\left(t_{3}\right)$. In this paper we consider exposure activities after instant t3. The aim is to analyze conditions to continue evacuation activities after the final event occurs. After t3, the mitigation actions of civil and military forces start with specific relief vehicles.

It is possible to identify two relief vehicle typologies:

- for the essential distribution of food and goods (e.g. tents, mobile emergency medical structures);

- for working in the affected area (e.g. trucks, hydraulic excavators).

\subsection{Zoning, work classes and resources}

By means of emergency logistics it is possible to reduce disaster impacts. Emergency logistics is a process of planning, managing and controlling the efficient flows of relief, information, and services from the points of origin to the points of destination to meet the urgent needs of the affected people under 
emergency conditions where resources can be allocated according to operational environments [4].

A model for resource allocation identifies three relevant elements for an earthquake event [9]:

- zoning;

- work classes;

- resources.

Zoning is a classification of the affected area as:

- SAR (Search-And-Rescue), where there are places with people trapped by primary disasters. depending on the workload, we can distinguish between spontaneous SAR, light SAR, intensive SAR. We only consider light and intensive SAR where specialized teams and equipment are needed. Instead, spontaneous SAR work is characterized by the emergence of on-the-spot citizen rescue groups;

- SA (Stabilizing areas), where there are places with people endangered by secondary disasters (damaged dams or damaged buildings with high risk of collapse). The population has to be evacuated out of these areas and further work to prevent the secondary disaster has to be initiated. It has to be considered that the probability for secondary disasters may be variable in time and that work at the potential secondary disaster sites decreases the related failure probability;

- $R A$ (Rehabilitation areas), where there are road infrastructures to be repaired to allow access to other important areas, such as hospitals, and to improve transportation times.

The areas set define operational area $O A$ where resources can be allocated.

Work classes are a set of activities according to different areas identified by zoning. Work classes are common to three areas, these are: rescue, lift, load, transport, spread, compact.

Resources are the relief vehicles to allocate for each work classes according to zoning. These are, for instance, cranes, hydraulic excavators, wheeled loaders, trucks, dozers and rollers.

Figure 1 shows areas identified by zoning, elementary work classes for each area and resources for each work class.

If the disastrous event is different to an earthquake, the model above allows us to also identify zoning, work classes and resources. For instance, if the disastrous event is a spill of hazardous material from a truck, the area is only SAR, the resources can be hydraulic excavators, cranes and trucks, and the work classes can be lift, load and transport (Figure 2).

After instant $t_{3}$, when the final effect occurs and evacuation activities are not possible, exposure risk component $\mathrm{N}$ depends on zoning $\mathrm{Z}$, work classes $\mathrm{WC}$ and resources $\mathrm{R}$ :

$$
\mathrm{N}_{\mathrm{t}>\mathrm{t}_{3}}=\mathrm{N}[\mathrm{Z}, \mathrm{WC}, \mathrm{R}]
$$


In Italy, the Linee guida ministeriali per la costituzione della colonna mobile regionale [10] and the Indirizzi operativi per la gestione delle emergenze [11] show how to identify the resources according to risk typology (e.g. flood; landslide) in terms of vehicles and equipment (e.g. numbers of ambulances and fire trucks). These documents give the way to identify zoning, work classes and resources.

Areas

\section{Work}

Resources

classes

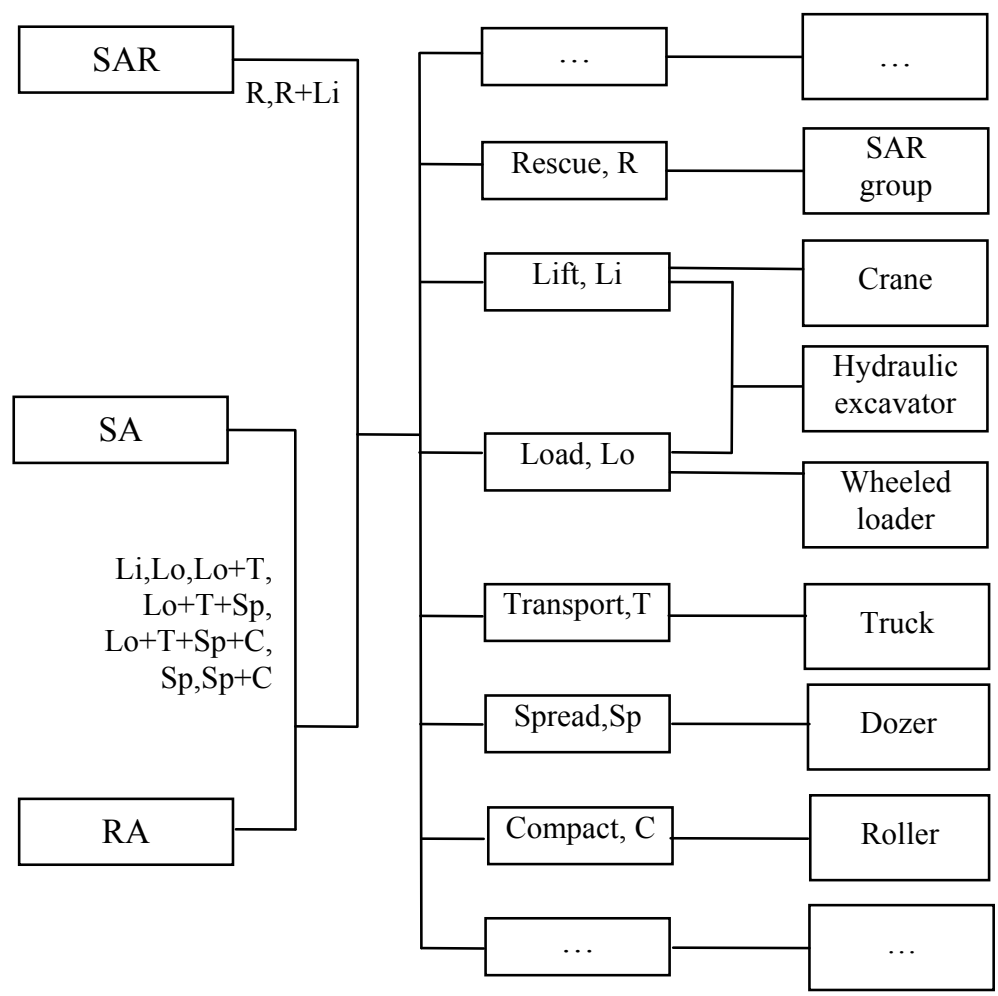

Figure 1: Areas, elementary work classes and the corresponding resources for an earthquake [9]. 


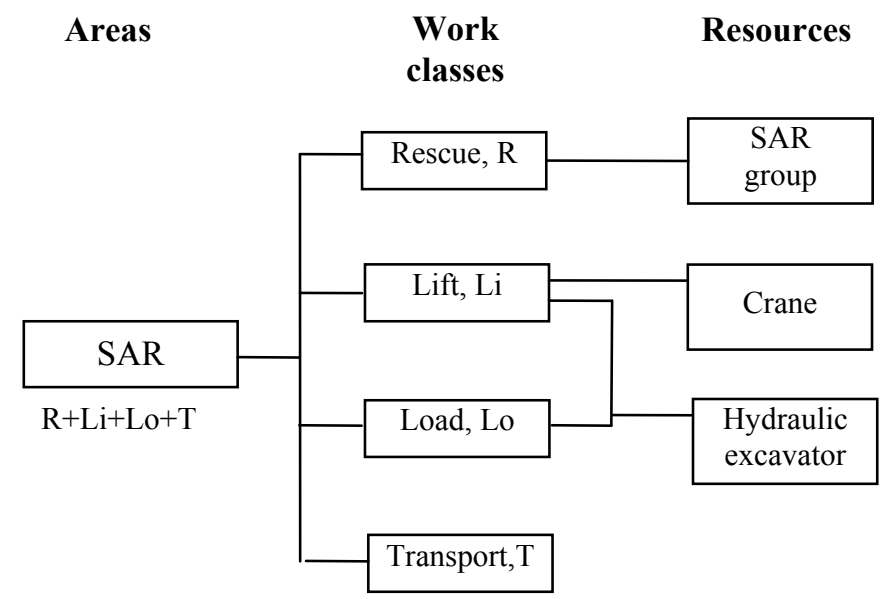

Figure 2: Areas, elementary work classes and resources for a spill of hazardous material from a truck.

\section{Distribution channels}

We consider the relief means and their distribution channels, considering, in a first approach, the resources introduced in the previous section.

To identify distribution channels in emergency logistics, the process must be explicated by two different facets: inbound logistics to relief distribution centres (termed the phase of relief supply), and outbound logistics from relief distribution centres to the affected areas (termed the phase of relief distribution) [4].

According to inbound logistic and outbound logistic definitions, we can consider two resource distribution channels models $[12,13]$ :

- Point to point, where there is a fusion of inbound and outbound logistics to each area of zoning from military or civil bases;

- Transhipment, where there are inbound logistics to relief distribution centres from military or civil bases and outbound logistics from relief distribution centres to each area of zoning.

It is useful to divide the geographical area to be analyzed into traffic zones and approximate all points at the beginning and end of trips in each zone with one point (centroid). In the geographical area to be analyzed, internal and external centroids can be identified [12]:

- $o$ is the set of internal zone centroids where there are areas classified by zoning and where to get relief vehicles;

- $\quad d$ is the set of internal zone centroids where there are relief distribution centres;

- $\quad w$ is the set of internal zone centroids where there are the depots of relief vehicles; 
- $\quad z$ is the set of external zone centroids where there are the depots of relief vehicles;

According to these sets of internal and external zone centroids, two main relief vehicles trip typologies can be identified (Figure 3):

- without any contact points (directly), where relief vehicles go to affected areas in $o$ from depots of relief vehicles in $w$ or $z$;

- with one contact point (not directly), where relief vehicles before going to relief distribution centres in $d$ from depots in $w$ or $z$ and after they go to the affected areas in $o$ from to relief distribution centres in $d$;

Direct trip typology characterizes point to point model, indirect trip typology characterizes transhipment model.

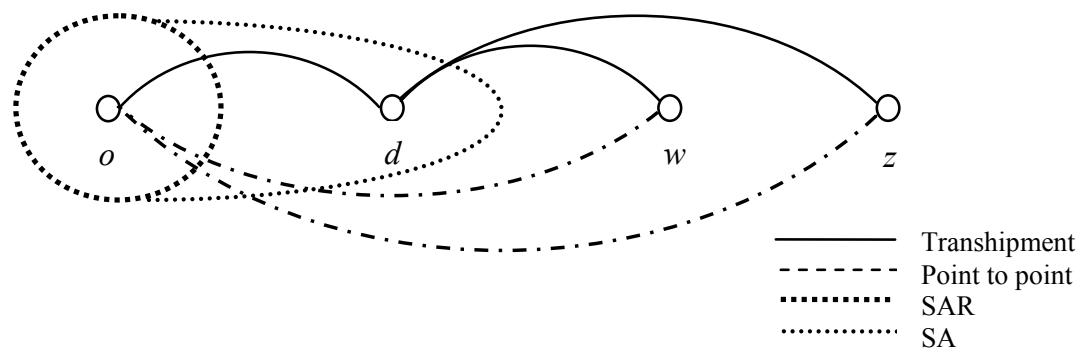

Figure 3: Trip typologies.

In this note we consider distribution channel models only for relief vehicles that are working in the affected area.

The point to point model assumes that we must minimize relief time $\left(t_{\mathrm{SAR}}, \mathrm{t}_{\mathrm{SA}}\right.$, $t_{R A}$ ) between the relief vehicles' departure from the depot in military or civil bases in $w$ o $z$ to the affected area in $o$ with a direct trip (Figure 4).

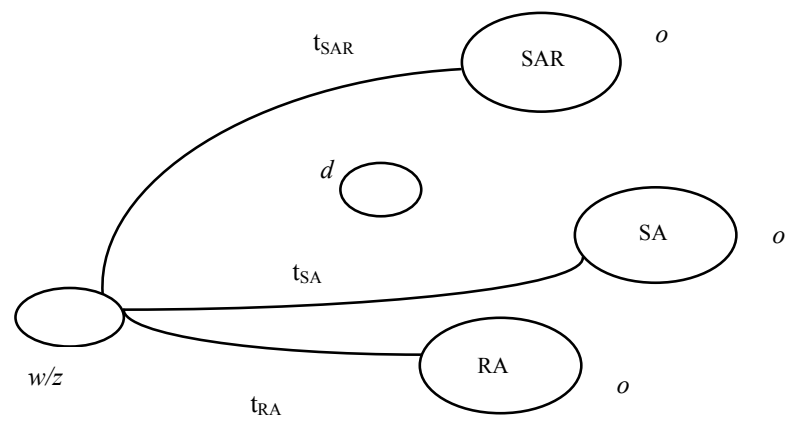

Figure 4: $\quad$ Point to point. 
The transhipment model (Figure 5) assumed that we must minimize the sum of relief time $\left(t_{\mathrm{SAR}}, \mathrm{t}_{\mathrm{SA}}, \mathrm{t}_{\mathrm{RA}}\right)$ between the relief vehicles' departure from the depot in military or civil bases in $w$ o $z$ to the distribution centre in $d$, and relief time $\left(\mathrm{t}_{\mathrm{w} / \mathrm{z}-\mathrm{d}}\right)$ between the relief vehicles' departure from the distribution centre in $d$ to the area in $o$ with an indirect trip. We consider two trips:

- inbound logistic, according to the relief vehicles' time between the depot in $w$ o $z$ and the distribution centre in $d$;

- outbound logistic, according to the relief vehicles' time between the distribution centre in $d$ and the area in $o$.

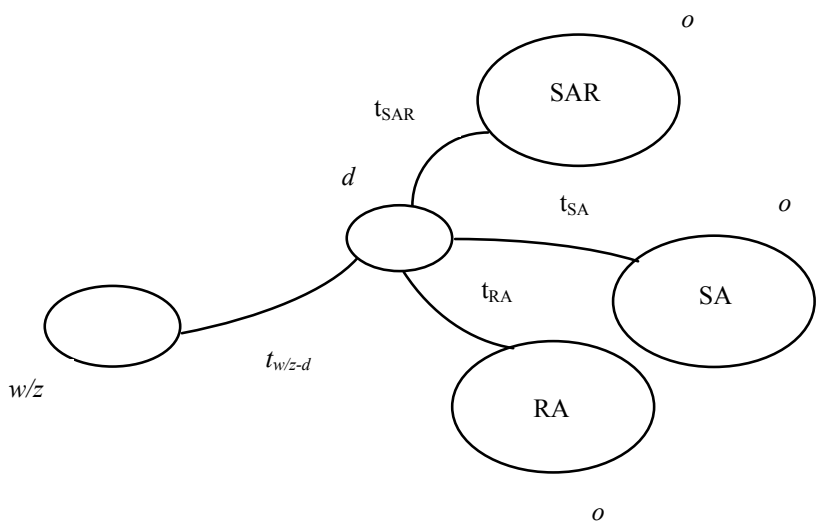

Figure 5: Transhipment.

Distribution channels models can be integrated with relief vehicles' paths and routes optimization models [14-18] and assignment models [19, 24].

\section{Conclusions}

Emergency logistic processes contribute to reduce disaster impacts after an event occurs by the organization and distribution of resources. After the time when the final effect occurs and people cannot be rescued, resources must be identified to continue from one side, people evacuation and from the other side, the arrival of relief in terms of different resources. The resources can be allocated with respect to zoning of the affected area and to work classes identified according to zoning. The two distribution channels models proposed allowing us to allocate resources are point to point and transhipment.

The research area that can be termed "Humanitarian logistic" considers that complementarily with resource allocation models and managerial protocols, further theoretical models are required to evaluate the ability of a transport system during and after emergencies and disasters. The development of such models requires operational research and logistical theories [25]. 
Further work is needed to analyze relief time mathematical formulation of resources for point to point and transhipment models.

\section{References}

[1] Russo F. and Vitetta A., Risk evaluation in a transportation system. International Journal of Sustainable Development and Planning, 1 (2), pp. 170-191, 2006.

[2] Russo F. and Vitetta A., Safety of users in road evacuation: General methodology and main results. WIT Transactions on the Built Environment, Volume 96, Urban Transport XIII, Urban Transport and the Environment in the 21st century, pp. 763-772, 2007.

[3] Russo F., Analisi dei sistemi di trasporto nell'ambito di scenari di rischio antropici e naturali. Evacuazione dei sistemi urbani. Metodi quantitativi per l'analisi di un sistema di trasporto in condizioni di emergenza. Franco Angeli, Milano. ISBN 1-84564-026-8, 2004.

[4] Challenges of emergency logistics management. Editorial. Transportation Research E, 43, pp. 655-659, 2007.

[5] Russo F. and Rindone C, Dalla pianificazione alla progettazione dei sistemi di trasporto: Processi e prodotti, Franco Angeli, Milano, 2007.

[6] Russo F. and Chilà G., Safety of users in road evacuation: demand models. WIT Transactions on the Built Environment, Volume 96, Urban Transport XIII, Urban Transport and the Environment in the 21st century, Brebbia C. A. (ed.), WIT Press, Southampton, pp. 773-782, 2007.

[7] Australia Governments, Emergency Management Approaches, http://www.ema.gov.au/ (last access January, 2011).

[8] USA, Department of Homeland Security Report to congress on catastrophic hurricane evacuation plan evaluation. www.fhwa.dot.gov/reports/ hurricanevacuation/ (last access January, 2011).

[9] Fiedrich, F. et al., Optimized resources allocation for emergency response after earthquake disasters, in Safety science, vol. 35, 2000.

[10] Regione Emilia Romagna, Linee guida ministeriali per la costituzione delle colonne mobili regionali. Documento approvato dalla giunta regionale con delibera $\mathrm{n}^{\circ} 2320$ del 10/12/1998 www.prometeobaricella.it/doc/Legge Linee_guida.pdf, 1998 (last access December 2011).

[11] Direttiva del Presidente del Consiglio dei Ministri, Indirizzi operativi per la gestione delle emergenze del 3 Dicembre 2008, http:// www.sindirvvf.it/ Documenti/Norme/Pocket $\% 20$ Norme/Soccorso/DPCM\%203_12_2008\%20 $\%$ 20Indirizzi $\% 20$ operativi\%20per\%20la\%20gestione $\% 20$ delle $\% \overline{2} 0$ emerge nze.htm, 2008 (last access December 2011).

[12] Russo F. and Comi A., A modeling system to simulate goods movements at an urban scale. Transportation, Vol.37, Issue 6, pp. 987-1009, 2010.

[13] Russo F., Polimeni A. and Vitetta A., Goods movement simulation in urban areas: a proposed approach. Trasporti Europei, 46(3), pp. 3-23. ISSN 18253997, 2010. 
[14] Vitetta A., Quattrone A. and Polimeni A., Safety of users in road evacuation: design of path choice models for emergency vehicles. WIT Transactions on the Built Environment, Volume 96, Urban Transport XIII, Urban Transport and the Environment in the 21st century, Brebbia C. A. (ed.), WIT Press, Southampton, pp. 803-812, 2007.

[15] Vitetta A., Quattrone A. and Polimeni A., Safety of users in road evacuation: algorithms for path design of emergency vehicles. WIT Transactions on the Built Environment, Volume 101, Urban Transport XIV, Urban Transport and the Environment in the 21st century, Brebbia C. A. (ed.), WIT Press, Southampton, pp. 727-737, 2008.

[16] Vitetta A., Quattrone A. and Polimeni A., Safety of users in road evacuation: Modelling and DSS for paths design of emergency vehicles. WIT Transactions on Ecology and the Environment, Volume 120, Sustainable Development and Planning IV, vol.1, Brebbia C. A. (ed.), WIT Press, Southampton, pp. 485-495, 2009.

[17] Polimeni A. and Vitetta A., Dynamic vehicle routing in road evacuation: a model for route design. WIT Transactions on the Built Environment, Volume 116, Urban Transport XVII, Urban Transport and the Environment in $21^{\text {st }}$ Century, Pratelli and Brebbia C. A. (ed.), WIT Press, Southampton, pp. 627-638, 2011.

[18] Polimeni A. and Vitetta A., Dynamic vehicle routing in road evacuation: route design experimentation. WIT Transactions on the Built Environment, Volume 117, Safety and Security engineering IV, Guarascio M., Reiners G. Brebbia C. A. and Garzia F. (ed.), WIT Press, Southampton, pp. 391-402, 2011.

[19] Vitetta A., Musolino G. and Marcianò F.A., Safety of users in road evacuation: Supply and demand-supply interaction models for users. WIT Transactions on the Built Environment, Volume 96, Urban Transport XIII, Urban Transport and the Environment in the 21st century, Brebbia C. A. (ed.), WIT Press, Southampton, pp. 783-792, 2007.

[20] Vitetta A., Musolino G. and Marcianò F. A., Safety of users in road evacuation: calibration of cost functions and simulation. WIT Transactions on the Built Environment, Volume 101, Urban Transport XIV, Urban Transport and the Environment in the 21st century, Brebbia C. A. (ed.), WIT Press, Southampton, pp. 715-725, 2008.

[21] Vitetta A., Musolino G. and Marcianò F.A., Safety of users in road evacuation: Modelling and DSS for transport supply and supply-demand interaction. WIT Transactions on Ecology and the Environment, Volume 120, Sustainable Development and Planning IV, vol.1, Brebbia C. A. (ed.), WIT Press, Southampton, pp. 475-484, 2009.

[22] Musolino G. and Vitetta A., Short-term forecasting in road evacuation: calibration of a travel time function. WIT Transactions on the Built Environment, Volume 116, Urban Transport XVII, Urban Transport and the Environment in $21^{\text {st }}$ Century, Pratelli and Brebbia C. A. (ed.), WIT Press, Southampton, pp. 615-626, 2011. 
[23] Marcianò F.A., Musolino G. and Vitetta A., Within day traffic assignment and signal setting in road evacuation: a procedure with explicit path enumeration. WIT Transactions on the Built Environment, Volume 117, Safety and Security engineering IV, Guarascio M., Reiners G. Brebbia C. A. and Garzia F. (ed.), WIT Press, Southampton, pp. 403-414, 2011.

[24] Quattrone A. and Vitetta A., Random and fuzzy utility models for road route choice. Transportation Research Part E: Logistics and Transportation Review, Volume 47, Issue 6, pp. 1126-1139.

[25] Taniguchi E, Ferreira F. and Nicholson A, A conceptual road network emergency model to aid emergency preparedness and response decision making in the context of humanitarian logistics, $7^{\text {th }}$ International Conference on City Logistics, Mallorca, 2011. 